\title{
Evaluating the performances of over-the-counter companies in developing countries using a stochastic dominance criterion and a PSO-ANN hybrid optimization model
}

\begin{abstract}
With suitable optimization criteria, hybrid models have proven to be efficient for preparing portfolios in capital markets of developed countries. This study adapts and investigates these methods for a developing country, so providing a novel approach to the application of banking and finance. Our specific objectives are to employ a stochastic dominance criterion to evaluate the performances of over-the-counter (OTC) companies in a developing country and to analyse them with a hybrid model involving particle swarm optimization and artificial neural networks.

In order to achieve these aims, we conduct a case study of OTC companies in Iran. Weekly and daily returns of 36 companies listed in this market are calculated for one year during 2014-2015. The hybrid model is particularly interesting and our results identify first, second and third-order stochastic dominances among these companies. Our chosen model uses the best performing combination of activation functions in our analysis, corresponding to TPT where $\mathrm{T}$ represents hyperbolic tangent transfers and P represents linear transfers.

Our portfolios are based on the shares of companies ranked with respect to the stochastic dominance criterion. Considering the minimum and maximum numbers of shares to be 2 and 10 for each portfolio, an eight-share portfolio is determined to be optimal. Compared with the index of Iran OTC during the research period of this study, our selected portfolio achieves a significantly better performance. Moreover, the methods used in this analysis are shown to be as efficient as they were in the capital markets of developed countries.
\end{abstract}

Keywords: Developing countries, portfolio optimization, stochastic dominance, particle swarm optimization, artificial neural networks. 


\section{Introduction}

The capital market is one of the most important economic sectors in any country. The development and prosperity of this market can have a great impact on economic growth. Moreover, high economic growth can then lead to the advancement of, and influence on, international interactions (Uddin et al., 2019). It is impossible to achieve desirable economic development and growth without the existence of efficient financial institutions and appropriate financing (Coulibaly et al., 2018; Alam et al., 2019).

Over-the-counter (OTC) companies collectively are one type of financial institution relating to the capital market, in which many assets are exchanged. Major disruptions were caused to OTCs and, more generally, capital markets as a result of the financial crisis in 2008. Their subsequent impact on financial systems indicates the important roles of these markets. To avert similar problems in future, it is necessary to evaluate the performance of capital markets and the companies operating in them.

Since the early 1960s, many researchers have paid attention to performance evaluation in capital markets. By proposing and testing various models, they studied the efficiency of different tools for conducting such analyses. These tools were specifically developed for application to the problems of considering the expected return of investors and the risk evaluation of investment options (Kristjanpoller et al., 2014; Ramos-Pérez et al., 2019). In this context, performance evaluation can be thought of as a feedback-and-control mechanism to increase the effectiveness of managing portfolio investments. It can also be used in the feedback mechanisms of optimization problems.

Investors involved in the capital market generally enter the market in order to obtain reasonable returns (Rahman et al., 2017). Thus, they need to evaluate their desired investment options in terms of return and risk. They should also take action in order to compare the performances of investment options, so that they can select and create optimal portfolios. Two approaches are commonly used to evaluate the performance of a portfolio.

The first approach is traditional mean-variance analysis (MVA) as specified by Markowitz (1952), which assumes a normal distribution model and utility functions of the second degree (Markowitz, 1952; Traynor, 1965; Jensen, 1969). Although often useful, this approach is neither appropriate nor efficient if the distribution of returns is not normal or the investors' utility function is not of the second degree (Lean et al., 2010).

The second approach involves the relatively new paradigm of stochastic dominance (SD) and presents a systematic framework to analyse behaviour in uncertainty, according to several studies (Hanoch and Levy, 1969; Whitmore, 1970; Hadar and Russell, 1971; Gosciniak, 2014; Ramos-Pérez et al., 2019). Stochastic dominance is a popular method for comparing two random variables through comparisons between their cumulative distribution functions (Montes et al., 2014). This criterion is also one of the most useful decision-making tools for evaluating and ranking the performances of investment options (Wong and Chan, 2008), as it provides a framework to evaluate such options in uncertain conditions (Fong, 2010). 
Stochastic dominance has nonparametric properties and depends only on some general assumptions that do not require analysts to identify complete parametric characteristics of investors' preferences and probability distributions of investment options (Lean et al., 2010). Consequently, SD is a popular criterion for use in performance evaluation and is efficient regardless of the normality or non-normality of returns distributions and the precise specifications of investors' utility functions. Furthermore, this criterion employs the whole empirical distribution rather than merely referencing the first two moments using parameters for the mean and variance (Denuit et al., 2014).

Previous studies that investigate stochastic dominance compare variations in the strictness of this performance criterion in different financial areas such as portfolio management and portfolio optimization (Roman et al., 2013; Al-Khazali et al., 2014; Clark and Kassimatis, 2014; Hsiao et al., 2019). These include first-order (FSD), second-order (SSD) and third-order (TSD) stochastic dominance. These studies find that the higher orders of this criterion, SSD and TSD, are more efficient for preparing optimal portfolios at zero cost and without cardinality limitations, in comparison with other portfolio indices. Moreover, the implementation of SSD and TSD in portfolio analysis can create positive returns in the long term, compared with negative returns in the corresponding market (Post and Kopa, 2013).

Optimisation should not usually be conducted over one investment period and should instead be undertaken with reference to the long term, though this subjective measure varies according to individual requirements. As investors allocate their wealth to assets that generate the highest expected returns (Liu et al., 2012), investment optimization is another important category to consider alongside performance evaluation. Portfolio optimization may also be interpreted as the allocation of wealth to some desirable investment options while the expected return and risk feature among other parameters in the problem (Deng et al., 2012).

Some of the best-known procedures for performance evaluation include genetic algorithms (GA) (Liu et al., 2012) and particle swarm optimization (PSO) (Kennedy and Eberhart, 1995; Pedersen and Chipperfield, 2010; Das et al., 2013; Leboucher et al., 2018). PSO was first used by Kennedy and Eberhart in 1995 to solve nonlinear problems and is an optimization technique that operates with stochastic excursion in a population. It is more popular than GA because it requires considerably fewer computing overheads (Cabrerizo et al., 2013).

In PSO, the population is called a swarm and the elements are called particles. Calculations are particle-based and the best solution is determined by a suitable search algorithm. Each particle moves at an adaptable speed according to its history and that of other particles in the swarm and the most optimal positions occupied by each particle are stored in memory. The particle having the best position of all particles is selected as the teacher and other particles learn from it. In each phase of the algorithm's iteration or generation making, the previous best (PB) and global best (GB) are determined. Generations are updated in PSO until a stable relative position is attained or a maximum number of iterations is fulfilled. 
PSO is highly flexible as new models have been proposed to deal with specific problems, involving changes to the basic methodology and customisation of the search algorithm (Bagheri et al., 2014; Gosciniak, 2014; Liu et al., 2015; Leboucher et al., 2018). Importantly in our context, it has also been used in problems pertaining to portfolio optimization (Babaei et al., 2015). The advantage of using optimization methods like PSO is that they do not explicitly depend on the gradients of objective functions and so apply to a broad range of optimization problems. This feature is particularly useful when the gradient of an objective function cannot be determined analytically or is difficult to evaluate numerically.

Such challenges typically arise in artificial neural network (ANN) training, where the input and output stream of data can be easily calculated though parameters are hidden inside the network (Pedersen and Chipperfield, 2010). Many applications of ANN have been presented over the last two decades, especially in finance (Ticknor, 2013; Kristjanpoller et al., 2014; Araújo et al., 2015; Fan et al., 2015; Patel et al., 2015a, 2015b; Rather et al., 2015). Most of these studies combine ANN with other optimization methods and algorithms such as PSO, which has demonstrated considerable success in ANN training (Das et al., 2013).

The problem of optimizing investment portfolios has to allow for correlations among returns from the financial maintenance period under consideration if an asymmetric distribution of returns exists (Babaei et al., 2015). Therefore, it is desirable to select an appropriate criterion in order to prepare an optimal portfolio and prioritize investment options. Although a back-propagation technique is very popular in ANN training, it is time-consuming to train a network in this way and other methods such as PSO should be considered instead. In the hybrid combination of PSO and ANN, it is not the structure of a neural network that changes. Rather, the weighting method and training technique chosen for the network are the important aspects and these relate to PSO, so the only role ANN plays in this process is to reduce the errors.

Nevertheless, the return distribution of investment options has not been paid due attention in published studies that consider both performance evaluation and portfolio optimization. The current study avoids assuming that the return distribution is normal and considers the importance of over-thecounter companies in the capital market. It also adopts stochastic dominance as an efficient criterion to evaluate the performance of investment options. This requires us to determine the order of stochastic dominance among investment options and apply these orders to prepare an optimal portfolio in conjunction with a hybrid model based on PSO and ANN.

After determining the optimal portfolio, we compare it with a suitable index for the OTC market. We also compare our research results, as applied to the Iranian OTC market in a developing country, with those of studies conducted in developed countries, in order to investigate the efficiency of these methods. Thus, this paper adds to the limited literature relating to the use of PSO and ANN for businesses in developing countries. Developing countries generally tend to have inadequate infrastructure, which could cause additional barriers to business (Mendy and Rahman, 2019; Riahi 
and Hammami, 2019). Indeed, Mertzanis (2019) pointed out that firms experience financial constraints across developing countries. Moreover, they lack a strong rule of law (Rahman and Mendy, 2019). Therefore, policy aiming is within the existing institutional settings of developing countries, so the findings of this study could help businesses to develop and implement efficient portfolio decisions.

The remainder of this paper is organized as follows. Section 2 describes the concepts pertaining to stochastic dominance, while Section 3 presents descriptive statistics for the companies that we consider and details of the OTC market index. The concepts pertaining to the hybrid model used in this study are explained in Section 4 and our research findings are explored in Section 5. Finally, Section 6 presents the conclusions arising from our investigation and analyses.

\section{Stochastic Dominance}

According to the rules of microeconomics (Versijp, 2007), the stochastic dominance criterion is defined by the following characteristics: 1) non-satiation, where investors prefer more or less of an item to an exact amount; 2) risk aversion, where investors prefer a certain revenue to an uncertain revenue of equal expectation; 3) skewness preference, where investors prefer a distribution with positive skewness. The resulting utility gains are positive in all three cases.

FSD, SSD and TSD are the most common measures of stochastic dominance, each of which generates a distinct decision-making problem with respect to its particular specification. FSD is a sufficient condition for SSD and SSD is a sufficient condition for TSD, so SSD is a subset of FSD and TSD is a subset of SSD.

In FSD, the assumption is that decision-makers prefer larger expected returns to smaller expected returns, regardless of whether they are risk loving, risk averse or risk neutral. Therefore, the resulting expected utility gain is positive (Fong, 2010). Investment opportunity $F$ has first-order stochastic dominance over investment opportunity $G$ if $E_{F}\{u(x)\} \geq E_{G}\{u(x)\}$ for investment return $x \in[a, b]$ and increasing utility function $u(x)$ such that $u^{\prime}(x) \geq 0$. In terms of the corresponding cumulative distribution functions $F(x)$ and $G(x)$, FSD implies that $F$ dominates $G$ if and only if $F(x) \leq G(x) \forall x$ and $\exists x: F(x)<G(x)$. This means that $F$ has first-order stochastic dominance over $G$ if the cumulative distribution function of returns for $F$ is always less than or equal to that for $G$, with strict inequality for some value of $x$ (Levy, 2006). Hence, the FSD criterion requires

$I_{1}(x)=G(x)-F(x) \geq 0$.

One of the main assumptions of SSD is that the investor is risk averse and so seeks to maximise expected utility while ensuring predictability of investment (Roman et al., 2013). SSD is generally 
regarded as more efficient than FSD under this condition because it is less restrictive. According to SSD, investment opportunity $F$ has second-order stochastic dominance over investment opportunity $G$ if $E_{F}\{u(x)\} \geq E_{G}\{u(x)\}$ for increasing and concave utility function $u(x)$ such that $u^{\prime}(x) \geq 0$ and $u^{\prime \prime}(x) \leq 0$. In terms of the corresponding cumulative distribution functions, SSD implies that $F$ dominates $G$ if and only if

$I_{2}(x)=\int_{a}^{x}\{G(t)-F(t)\} d t \geq 0$

for all $x \in[a, b]$ with strict inequality for some value of $x$.

In TSD, a further constraint is added to the risk-averse criterion of SSD. In this case, investment opportunity $F$ has third-order stochastic dominance over investment opportunity $G$ if $E_{F}\{u(x)\} \geq$ $E_{G}\{u(x)\}$ for increasing, concave and positively skewed utility function $u(x)$ such that $u^{\prime}(x) \geq 0$, $u^{\prime \prime}(x) \leq 0$ and $u^{\prime \prime \prime}(x) \geq 0$. An equivalent definition of TSD using cumulative distribution functions states that $F$ dominates $G$ if and only if

$I_{3}=\int_{a}^{x} \int_{a}^{t}\{G(s)-F(s)\} d s d t \geq 0$

for all $x \in[a, b]$ with strict inequality for some value of $x$. The existence of a greater mean, a smaller variance and a greater skewness determine which investment opportunity would be preferable.

\section{Input Data}

The investment options investigated in this study include all the OTC companies listed in Iran for a period of one year during 2014-2015. The inclusion criteria are; 1) the company started its OTC activities before $21^{\text {st }}$ March 2014 and continued until $20^{\text {th }}$ March 2015; 2) the company's stocks were listed in the OTC market; 3) the company did not operate in investment and holding areas.

According to these inclusion criteria, 36 companies were eligible for analysis in this study. Only their trademarks are used for reporting the results of our analyses in this paper. The data used in this study were supplied by the Tehran Securities Exchange Technology Management Company and extracted from the website www.ifb.ir. The weekly and daily returns of the selected companies were calculated by considering the dividend as

$R_{t}=\frac{D_{t}}{P_{t-1}}+\frac{P_{t}+P_{t-1}}{P_{t-1}}$ 
where $R_{t}$ is the return in period $t, P_{t}$ is the share price at the end of the maintenance period, $P_{t-1}$ is the share price at the beginning of the maintenance period and $D_{t}$ is the cash interest during the maintenance period.

During the study period, 52 weekly returns (1,872 in total) and 241 daily returns (8,676 in total) were obtained for each company. The weekly returns were used to investigate dominance among the companies and daily returns were employed to train the hybrid model of PSO and ANN. Table 1 presents descriptive statistics of returns for all these companies within the Iranian over-the-counter market.

According to this table, the majority of mean returns for these companies were negative during the study period, with the best returns achieved by Mafakher and Hasina. Given the status of market value in Iran, it is also important to consider the levels of fluctuation. According to Table 1, Hasina shares displayed the highest level of fluctuation, with greatest standard deviation and skewness. The lowest return among these trademarks was recorded for Kemarjan.

Table 1: Descriptive statistics and normality tests for OTC companies.

\begin{tabular}{|c|c|c|c|c|c|c|c|c|}
\hline \multirow[b]{2}{*}{ Trademark } & \multirow{2}{*}{ 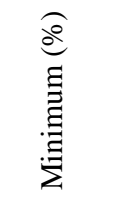 } & \multirow{2}{*}{ 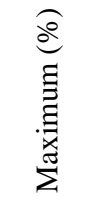 } & \multirow{2}{*}{ 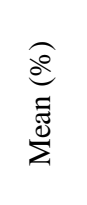 } & \multirow{2}{*}{$\begin{array}{l}\widehat{Q} \\
\dot{d} \\
\stackrel{0}{0} \\
\stackrel{\vec{D}}{\omega}\end{array}$} & \multirow{2}{*}{ 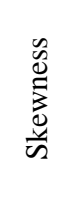 } & \multirow{2}{*}{ 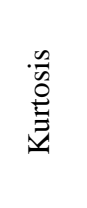 } & \multicolumn{2}{|c|}{ JB Test } \\
\hline & & & & & & & 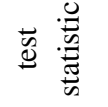 & 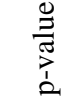 \\
\hline $\mathrm{ACP}$ & -53.88 & 11.39 & -1.58 & 9.34 & -3.93 & 19.97 & 826.9 & 0.001 \\
\hline Afra & -69.65 & 19.80 & -1.79 & 11.76 & -3.71 & 22.01 & 965.1 & 0.001 \\
\hline Arfa & -13.93 & 21.48 & -0.42 & 5.84 & 0.81 & 2.53 & 15.7 & 0.006 \\
\hline Balas & -40.63 & 12.91 & -1.19 & 7.97 & -2.23 & 10.88 & 246.7 & 0.001 \\
\hline Bemapna & -10.46 & 11.82 & -0.22 & 4.89 & 0.55 & 0.31 & 2.5 & 0.149 \\
\hline Bepas & -16.82 & 4.44 & -0.22 & 2.99 & -3.60 & 18.61 & 714.3 & 0.001 \\
\hline Besama & -13.18 & 14.45 & -0.06 & 5.27 & 0.18 & 1.08 & 1.9 & 0.243 \\
\hline Toolid & -26.54 & 11.16 & -0.33 & 6.92 & -1.11 & 3.28 & 27.7 & 0.002 \\
\hline Dey & -13.81 & 9.95 & -0.24 & 4.77 & -0.66 & 0.25 & 5.9 & 0.039 \\
\hline Fezarin & -17.42 & 16.64 & 0.06 & 5.46 & 0.31 & 2.41 & 10.1 & 0.015 \\
\hline Foulay & -48.40 & 16.31 & -1.68 & 10.31 & -3.20 & 12.89 & 373.9 & 0.001 \\
\hline Ghaminou & -14.86 & 21.50 & 0.45 & 6.74 & 0.52 & 1.29 & 4.6 & 0.057 \\
\hline Ghashir & -16.57 & 10.92 & -1.83 & 6.15 & -0.06 & -0.26 & 0.3 & 0.500 \\
\hline Ghachar & -12.51 & 6.83 & -1.49 & 4.54 & -0.72 & 0.39 & 4.3 & 0.063 \\
\hline Hasina & -43.00 & 254.54 & 5.75 & 36.68 & -6.32 & 43.57 & 3687.2 & 0.001 \\
\hline Jam & -55.27 & 15.57 & -0.91 & 8.66 & -4.96 & 31.96 & 2005.6 & 0.001 \\
\hline $\mathrm{KBC}$ & -66.94 & 18.61 & -2.10 & 10.97 & -4.08 & 24.30 & 1176.5 & 0.001 \\
\hline Kemarjan & -100.00 & 19.56 & -2.29 & 15.23 & -5.28 & 34.33 & 2309.9 & 0.001 \\
\hline Keshargh & -7.73 & 6.29 & -0.12 & 3.10 & -0.31 & 0.56 & 1.1 & 0.452 \\
\hline Khorasan & -24.94 & 21.01 & 0.13 & 5.24 & -0.90 & 14.21 & 359.6 & 0.001 \\
\hline Mafakher & -11.26 & 16.78 & 5.75 & 5.58 & 0.75 & 1.59 & 8.4 & 0.021 \\
\hline Maroun & -32.90 & 20.42 & 0.09 & 6.68 & -2.25 & 13.61 & 364.8 & 0.001 \\
\hline Mihan & -13.54 & 18.65 & 0.76 & 6.38 & 0.74 & 1.25 & 6.7 & 0.031 \\
\hline Pakhsh & -17.18 & 12.56 & -0.45 & 5.80 & -0.55 & 0.44 & 2.7 & 0.138 \\
\hline Sebagh & -11.99 & 18.17 & 0.70 & 5.60 & 0.55 & 1.13 & 4.2 & 0.066 \\
\hline Semara & -10.16 & 22.62 & 1.08 & 6.72 & 1.25 & 2.60 & 23.6 & 0.002 \\
\hline Sharanel & -32.85 & 16.47 & 0.04 & 6.39 & -2.38 & 13.71 & 374.6 & 0.001 \\
\hline Shepas & -43.44 & 12.73 & -1.73 & 7.88 & -3.38 & 16.61 & 577.1 & 0.001 \\
\hline
\end{tabular}




\begin{tabular}{|c|cc|cc|cc|cc|} 
Sobhan & -45.78 & 11.98 & -0.27 & 7.80 & -3.92 & 22.79 & 1039.6 & 0.001 \\
Touril & -56.98 & 16.77 & -1.54 & 10.02 & -3.39 & 18.16 & 672.5 & 0.001 \\
Gardesh & -15.61 & 14.49 & -0.02 & 6.41 & -0.20 & 0.60 & 0.7 & 0.500 \\
Gostar & -16.18 & 17.72 & -1.41 & 4.46 & 0.03 & 0.38 & 4.3 & 0.065 \\
Zamin & -12.52 & 16.82 & 0.41 & 6.08 & 0.58 & 0.93 & 3.9 & 0.074 \\
Zagros & -50.78 & 9.42 & -1.49 & 7.63 & -5.41 & 35.43 & 2457.1 & 0.001 \\
Zangan & -29.35 & 14.27 & -1.36 & 7.04 & -1.00 & 4.24 & 38.2 & 0.001 \\
Zob & -12.34 & 8.70 & -1.41 & 4.46 & 0.03 & 0.38 & 0.1 & 0.500 \\
\hline Index & -8.62 & 3.53 & -0.05 & 1.16 & -1.40 & 12.66 & 1622.2 & 0.001 \\
\hline
\end{tabular}

In the last row of Table 1, aggregate information pertaining to descriptive statistics of the OTC market is also displayed. The mean daily growth rate of all companies was negative, with an average return of $-0.05 \%$. Put another way, any investors who invested in the index portfolio for this OTC market would have lost a share value of $0.05 \%$ on average. The Jarque-Bera (JB) test was used to investigate the normality and non-normality of the distribution of returns on each trademark and the index of the OTC market. According to the results of our JB tests, we note that the trademarks Bemapna, Besama, Ghaminou, Ghashir, Ghachar, Keshargh, Pakhsh, Sebagh, Vegardesh, Vezamin and Zob displayed normally distributed returns, whereas those for the index and other trademarks displayed non-normal distributions.

\section{4. $\quad$ PSO and ANN Hybrid Model}

\subsection{PSO}

Particle swarm optimisation is a numerical optimisation strategy whereby all particles use evolving sets of information to change their positions in order to iterate towards the best response. For each particle $i$, this information includes its current position, current velocity, distance between current position and particle best, and distance between current position and global best. The particle's velocity is updated iteratively for $k=0,1,2, \ldots$ using the equation

$v_{i}^{k+1}=w v_{i}^{k}+c_{1} r_{1}\left(\right.$ Pbest $\left._{i}-x_{i}^{k}\right)+c_{2} r_{2}\left(\right.$ Gbest $\left.-x_{i}^{k}\right)$.

In this equation, $x_{i}^{k}$ and $v_{i}^{k}$ are the current position and velocity of particle $i$ at iteration $k$. Also, $w$ is the inertia coefficient or weight parameter, $c_{1}$ and $c_{2}$ are acceleration coefficients, and $r_{1}$ and $r_{2}$ are random numbers in $[0,1]$. Finally, Pbest $_{i}$ is the current best position of particle $i$, and Gbest is the current best position in the population or swarm. The position of each particle is then updated iteratively using the equation

$x_{i}^{k+1}=x_{i}^{k}+v_{i}^{k+1}$. 


\subsection{ANN}

ANN is trained with two series of data. The first series includes data considered to be the input, whereas the second series consists of the output data. The data for training the network involve input weights (IW) that enter the neurons of the latent layer. Using the layer weights (LW) and transfer function, they are then transferred to subsequent layers until they finally reach the output layer. Each neuron has a bias (B) and a transfer function that works on the input data within the network. Bias is a constant value that enters each neuron at different levels of the network input.

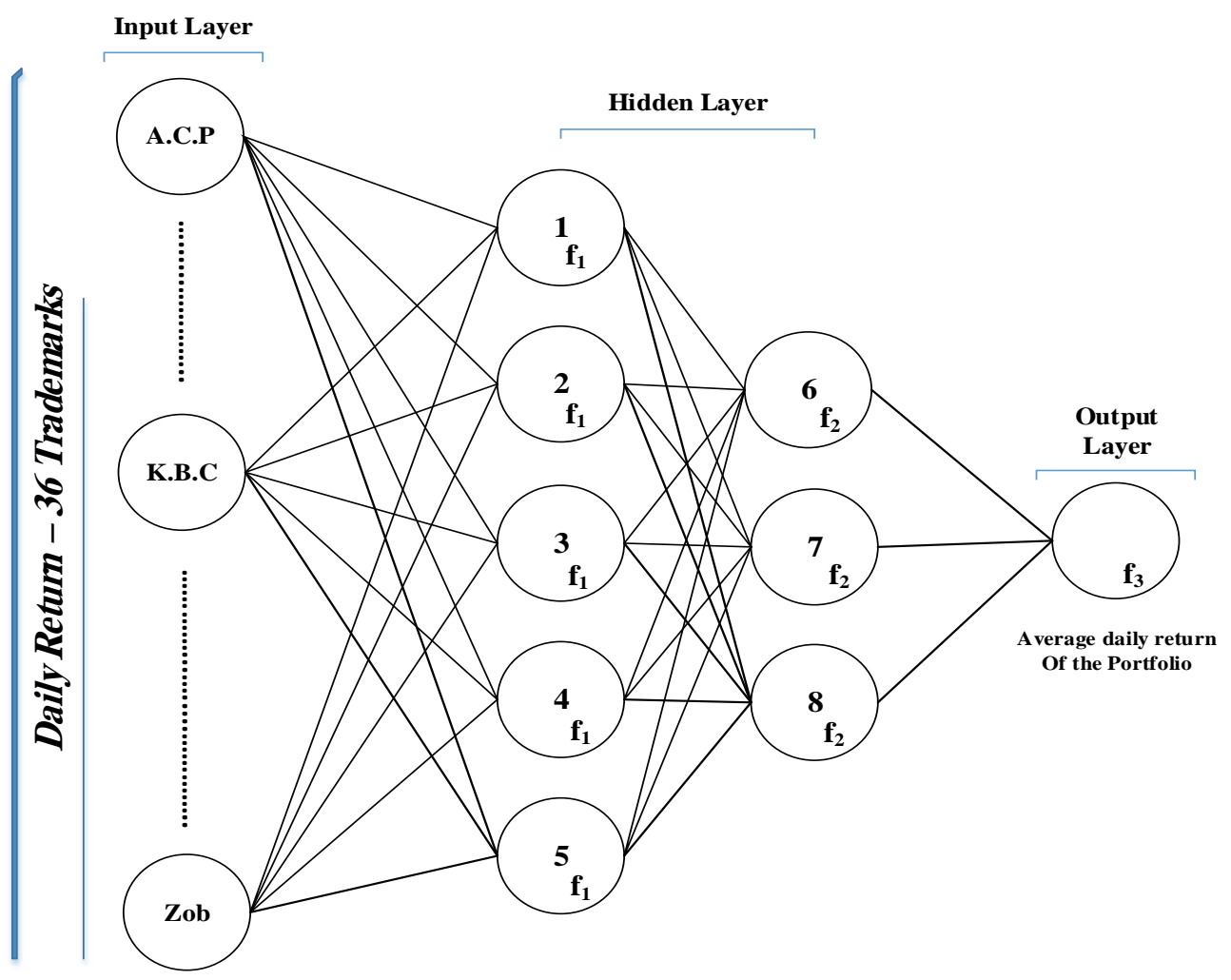

Figure 1: Artificial network architecture.

Figure 1 indicates a three-layer ANN that was used in our study after combining and training with PSO. The network has 36 inputs, each of which includes the daily period of trademarks. The latent or hidden layer includes two stages with 5 and 3 neurons respectively. The output layer has a neuron including the mean daily return of the trademarks after ranking by a suitable stochastic dominance criterion. The transfer function used in this study includes a combination of three forms, including the sigmoid tangent (Patel et al., 2015b; Das et al., 2013; Ticknor, 2013), linear (Patel et al., 2015a; Fan et al., 2015) and sigmoid logarithm transfer functions. 
The best combination of these functions is deemed to be that with the smallest number of errors. Hence, the number of three-function transfer combinations considered in this study is $3 \times 3 \times 3=$ 27. Moreover, root mean square error (RMSE) was used to evaluate the network performance. This is a simple transformation of the mean square error (MSE) (Ticknor, 2013) defined by

$$
M S E=\frac{1}{n} \sum_{i=1}^{n}\left(Y t s_{i}-Y t r_{i}\right)^{2}
$$

where $n$ is the sample size, $Y t s_{i}$ refers to the test data and $Y t_{i}$ represents the training data. RMSE is then the square root of MSE, expressed as a percentage thus:

$$
R M S E=100 \times \sqrt{M S E} .
$$

\subsection{Training the Network with PSO}

The training process for our network involves the following algorithm:

- Normalize the input data and select $80 \%$ of the data as training data.

- Form the network structure as [Input.5.3.Output].

- Train the network with PSO under the following conditions:

- use a maximum of 40 iterations to train the network;

- take the swarm size to be 200 for implementing PSO;

- evaluate the output parameters IW, LW and B after training.

All previous studies relating to applications of PSO investigated complicated structures for their algorithms (Pedersen and Chipperfield, 2010), so the current study aims to apply a simplified hybrid of ANN and PSO to improve upon this practice. The value and technical advantage of the current study arise mostly through generating appropriate rankings and preparing optimal portfolios based on these rankings.

\section{Research Findings}

\subsection{Empirical Findings Resulting from the Studied Trademarks}

The market index and all 36 trademarks were compared in pairs with appropriate stochastic dominance tests in order to determine their pairwise dominance orders and identify whether these dominances are first-order, second-order or third-order. To illustrate the results obtained, Table 2 
presents the orders of dominance among the first 5 companies and the last 5 companies from the list in Table 1, along with the market index. The key here is that F refers to FSD, S refers to SSD, T refers to TSD and $\mathrm{N}$ indicates non-order stochastic dominance (ND). The trademarks in each row represent dominating symbols, while the trademarks in each column represent dominated symbols. For example, Foulay (row 8) dominates over Afra (column 7) under TSD.

Table 2: Stochastic dominance orders for the selected trademarks.

\begin{tabular}{|c|c|c|c|c|c|c|c|c|c|c|c|}
\hline $\begin{array}{l}\text { Trading } \\
\text { Symbol }\end{array}$ & 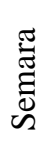 & 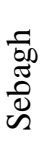 & 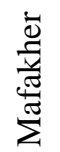 & 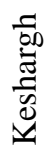 & 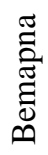 & 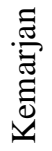 & $\underset{\&}{\mathbb{Z}}$ & $\frac{\overrightarrow{\mathrm{E}}}{\overline{0}}$ & $\begin{array}{l}\bar{\Xi} \\
\stackrel{0}{0}\end{array}$ & U্ & $\frac{\underset{d}{d}}{\stackrel{d}{\Xi}}$ \\
\hline Semara & - & $\mathrm{N}$ & $\mathrm{N}$ & $\mathrm{N}$ & $\mathrm{N}$ & $\mathrm{S}$ & S & $\mathrm{S}$ & $\mathrm{S}$ & $\mathrm{S}$ & $\mathrm{N}$ \\
\hline Sebagh & $\mathrm{N}$ & - & $\mathrm{N}$ & $\mathrm{N}$ & $\mathrm{N}$ & $\mathrm{S}$ & S & $\mathrm{S}$ & $\mathrm{S}$ & S & $\mathrm{N}$ \\
\hline Mafakher & $\mathrm{N}$ & $\mathrm{N}$ & - & $\mathrm{N}$ & $\mathrm{N}$ & $\mathrm{S}$ & $\mathrm{S}$ & $\mathrm{S}$ & $S$ & $S$ & $\mathrm{~N}$ \\
\hline Keshargh & $\mathrm{N}$ & $\mathrm{N}$ & $\mathrm{N}$ & - & $\mathrm{S}$ & $\mathrm{N}$ & S & $\mathrm{S}$ & S & $S$ & $\mathrm{~N}$ \\
\hline Bemapna & $\mathrm{N}$ & $\mathrm{N}$ & $\mathrm{N}$ & $\mathrm{N}$ & - & $\mathrm{S}$ & $\mathrm{S}$ & $\mathrm{S}$ & $\mathrm{S}$ & S & $\mathrm{N}$ \\
\hline Kemarjan & $\mathrm{N}$ & $\mathrm{N}$ & $\mathrm{N}$ & $\mathrm{S}$ & $\mathrm{N}$ & - & $\mathrm{N}$ & $\mathrm{N}$ & $\mathrm{N}$ & $\mathrm{N}$ & $\mathrm{N}$ \\
\hline Afra & $\mathrm{N}$ & $\mathrm{N}$ & $\mathrm{N}$ & $\mathrm{N}$ & $\mathrm{N}$ & $\mathrm{S}$ & - & $\mathrm{N}$ & $\mathrm{N}$ & $\mathrm{N}$ & $\mathrm{N}$ \\
\hline Foulay & $\mathrm{N}$ & $\mathrm{N}$ & $\mathrm{N}$ & $\mathrm{N}$ & $\mathrm{N}$ & $\mathrm{S}$ & $\mathrm{T}$ & - & $\mathrm{N}$ & $\mathrm{N}$ & $\mathrm{N}$ \\
\hline Touril & $\mathrm{N}$ & $\mathrm{N}$ & $\mathrm{N}$ & $\mathrm{N}$ & $\mathrm{N}$ & $\mathrm{S}$ & S & $\mathrm{N}$ & - & $\mathrm{N}$ & $\mathrm{N}$ \\
\hline $\mathrm{ACP}$ & $\mathrm{N}$ & $\mathrm{N}$ & $\mathrm{N}$ & $\mathrm{N}$ & $\mathrm{N}$ & $\mathrm{S}$ & S & $\mathrm{N}$ & $\mathrm{T}$ & - & $\mathrm{N}$ \\
\hline Index & $\mathrm{S}$ & $\mathrm{T}$ & $\mathrm{T}$ & $\mathrm{S}$ & $\mathrm{S}$ & $\mathrm{S}$ & S & $\mathrm{S}$ & $\mathrm{S}$ & S & - \\
\hline
\end{tabular}

If a risk-taking investor invests in a share which is dominated under FSD, it is better to change the investment option to the dominating symbol under FSD in order to increase the expected utility. At the same time, this will increase the expected wealth because there is an arbitrage opportunity in this order of dominance. Under the conditions existing in SSD and TSD, risk-taking and risk-averse investors can change their investments from companies that are dominated to companies that are dominant in order to maximize the expected utility and improve their statuses.

Among 481 stochastic dominances identified in this study, 6 were first-order dominances that provide risk-taking investors with arbitrage opportunities. There were also 365 second-order dominances and 110 third-order dominances, identification of which increases the expected utilities for risk-taking and risk-averse investors. According to the rules of stochastic dominance, the symbol having the greatest amount of dominating and the least amount of being dominated will offer the best performance. Table 3 indicates the number of dominances for all these companies and the market index, as a basis for determining the rankings as a guide for portfolio optimisation.

Table 3: Rankings of companies based on stochastic dominance criteria.

\begin{tabular}{|c|c|c|c|}
\hline $\begin{array}{c}\text { Trading } \\
\text { Symbol }\end{array}$ & $\begin{array}{c}\text { Number and order of } \\
\text { dominance for } \\
\text { dominating symbol }\end{array}$ & $\begin{array}{c}\text { Number and order of } \\
\text { dominance for } \\
\text { dominated symbol }\end{array}$ & $\begin{array}{c}\text { 悉 } \\
\simeq\end{array}$ \\
\hline
\end{tabular}




\begin{tabular}{|c|c|c|c|c|c|c|c|c|c|}
\hline & 空 & 宓 & $\stackrel{\hat{n}}{\hat{\omega}}$ & ఫ్ّ & 雳 & ڤิ & 悹 & స్ّ & \\
\hline Semara & 1 & 24 & 4 & 29 & 0 & 0 & 0 & 0 & 1 \\
\hline Sebagh & 0 & 25 & 4 & 29 & 0 & 0 & 0 & 0 & 2 \\
\hline Mafakher & 1 & 25 & 3 & 2 & 0 & 0 & 1 & 1 & 3 \\
\hline Keshargh & 0 & 20 & 9 & 29 & 0 & 1 & 0 & 1 & 4 \\
\hline Bemapna & 0 & 18 & 5 & 23 & 0 & 1 & 0 & 1 & 5 \\
\hline Bepas & 0 & 14 & 4 & 18 & 0 & 0 & 1 & 1 & 6 \\
\hline Mihan & 1 & 18 & 4 & 23 & 0 & 1 & 1 & 2 & 7 \\
\hline Hasina & 0 & 7 & 0 & 7 & 0 & 0 & 0 & 0 & 8 \\
\hline Zamin & 0 & 18 & 3 & 21 & 0 & 3 & 1 & 4 & 9 \\
\hline Besama & 0 & 17 & 3 & 20 & 0 & 4 & 1 & 5 & 10 \\
\hline Dey & 0 & 16 & 3 & 19 & 0 & 3 & 2 & 5 & 11 \\
\hline Ghaminou & 1 & 14 & 4 & 19 & 0 & 4 & 2 & 6 & 12 \\
\hline Fezarin & 0 & 12 & 3 & 15 & 0 & 0 & 5 & 5 & 13 \\
\hline Zob & 0 & 8 & 7 & 15 & 1 & 4 & 0 & 5 & 14 \\
\hline Khorasan & 0 & 15 & 0 & 15 & 0 & 2 & 4 & 6 & 15 \\
\hline Ghachar & 0 & 7 & 5 & 12 & 2 & 4 & 1 & 5 & 16 \\
\hline Arfa & 0 & 10 & 4 & 14 & 0 & 7 & 1 & 8 & 17 \\
\hline Gostar & 0 & 10 & 5 & 15 & 0 & 9 & 1 & 10 & 18 \\
\hline Gardesh & 1 & 9 & 3 & 13 & 0 & 6 & 4 & 10 & 19 \\
\hline Pakhsh & 0 & 9 & 4 & 13 & 0 & 11 & 1 & 12 & 20 \\
\hline Saranel & 0 & 11 & 1 & 12 & 0 & 3 & 10 & 13 & 21 \\
\hline Ghashir & 0 & 2 & 8 & 10 & 2 & 11 & 1 & 14 & 22 \\
\hline Toolid & 0 & 8 & 4 & 12 & 0 & 13 & 4 & 17 & 23 \\
\hline Maroun & 0 & 11 & 0 & 7 & 0 & 2 & 13 & 15 & 24 \\
\hline Zangan & 0 & 6 & 3 & 9 & 1 & 17 & 3 & 21 & 25 \\
\hline Sobhan & 0 & 7 & 2 & 9 & 0 & 14 & 9 & 23 & 26 \\
\hline Balas & 0 & 5 & 4 & 9 & 0 & 20 & 4 & 24 & 27 \\
\hline Zagros & 0 & 5 & 2 & 7 & 0 & 16 & 10 & 26 & 28 \\
\hline Shepas & 0 & 1 & 5 & 6 & 0 & 22 & 4 & 26 & 29 \\
\hline $\mathrm{KBC}$ & 1 & 3 & 1 & 5 & 0 & 29 & 2 & 31 & 30 \\
\hline Jam & 0 & 4 & 0 & 4 & 0 & 16 & 10 & 26 & 31 \\
\hline $\mathrm{ACP}$ & 0 & 3 & 1 & 4 & 0 & 25 & 4 & 29 & 32 \\
\hline Touril & 0 & 2 & 1 & 3 & 0 & 28 & 3 & 31 & 33 \\
\hline Foulay & 0 & 1 & 1 & 2 & 0 & 26 & 3 & 29 & 34 \\
\hline Afra & 0 & 1 & 0 & 1 & 0 & 31 & 2 & 33 & 35 \\
\hline Kemarjan & 0 & 1 & 0 & 1 & 0 & 31 & 2 & 33 & 35 \\
\hline Index & 0 & 26 & 6 & 29 & 0 & 0 & 0 & 0 & 0 \\
\hline
\end{tabular}

According to Table 3, the trademark Semara was FSD dominant over 1 symbol, SSD dominant over 24 symbols and TSD dominant over 4 symbols, representing aggregate domination over 29 symbols. Moreover, it was not dominated by any symbols and so was ranked first in terms of 
performance. After Semara, the trademarks Sebagh and Mafakher were ranked in second and third positions. At the bottom of Table 3, the trademarks Afra and Kemarjan were jointly ranked in $35^{\text {th }}$ place due to identical results for their stochastic dominance orderings. Regarding the orders of dominance between the index and other trademarks, Table 3 indicates that the index was SSD dominant over 23 symbols and TSD dominant over 6 symbols. This represents aggregate dominance over 29 symbols, without being under any dominance.

An optimal portfolio is next prepared, using the rankings based on stochastic dominance order as presented in Table 3. Before preparing this optimal portfolio, we impose some constraints on the calculations:

1. the desired portfolio should have at least 2 and at most 10 shares;

2. the output at each stage is the current daily mean for each trademark;

3. RMSE is the evaluation criterion for the training data and the test data.

The daily means of the possible portfolios were calculated to determine the network outputs. These are presented in Table 4 and we note that the mean of daily returns calculated for 6 of the 9 portfolios were initially negative. Assuming that investments are all in capital markets with a preference for more return rather than less return, the results are unexpected because no reasonable investor would adopt the first 6 portfolios. The best options are to select the $7^{\text {th }}, 8^{\text {th }}$ and $9^{\text {th }}$ portfolios, which generate the best returns due to the positivity of the mean of daily returns as the network output.

Table 4: Structures and return means of 9 daily portfolios.

\begin{tabular}{|c|c|c|c|c|c|c|c|c|c|}
\hline Portfolio & 1 & 2 & 3 & 4 & 5 & 6 & 7 & 8 & 9 \\
\hline $\begin{array}{c}\text { Ranked marks based } \\
\text { on stochastic } \\
\text { dominance }\end{array}$ & $1-2$ & $1-3$ & $1-4$ & $1-5$ & $1-6$ & $1-7$ & $1-8$ & $1-9$ & $1-10$ \\
$\begin{array}{c}\text { Mean of daily } \\
\text { returns (\%) }\end{array}$ & -0.029 & -0.030 & -0.083 & -0.097 & -0.046 & -0.044 & 1.706 & 0.948 & 0.436 \\
\hline
\end{tabular}

The negative means for dominant companies require further explanation. We used weekly and daily returns for our analysis, the former to investigate dominance among the companies and the latter to train the hybrid model. The 2014 Iranian stock market unusually experienced huge fluctuations because of government subsidies, increasing production, market recession and regional politics. Consequently, most of the daily means were negative in contrast with the weekly averages of dominant companies that were positive.

Given that there are three output states and 27 three-member combinations of activation functions for training the network, 81 models were investigated in order to identify the model with the smallest number of errors. This model could then be presented as the optimal portfolio with corresponding 
weights. As we identify some sub-optimal models during the training process, we present only those models with the smallest number of errors as results of training the network. Tables 5, 6 and 7 display these results for the portfolios comprising 7, 8 and 9 symbols, respectively. According to these tables, the portfolios having 4, 8 and 9 shares of TPT, TPT and PTT models contain the smallest errors, whereas the PPP, LTP and LTP models contain the largest errors.

Table 5: Optimal models for Portfolio 7.

\begin{tabular}{|c|c|c|}
\hline \multicolumn{3}{|c|}{ Portfolio 7} \\
Activation Function Admixture & $\mathrm{RMSE}_{\mathrm{tr}}(\%)$ & $\mathrm{RMSE}_{\mathrm{ts}}(\%)$ \\
\hline TPT & 0.109 & 0.083 \\
PTT & 0.077 & 0.173 \\
TPP & 0.146 & 0.180 \\
TTT & 0.139 & 0.487 \\
LPT & 0.187 & 0.173 \\
LTP & 0.045 & 1.322 \\
LLT & 0.058 & 1.316 \\
TLP & 0.073 & 1.308 \\
LPP & 0.082 & 1.311 \\
PLT & 0.083 & 1.286 \\
TLT & 0.086 & 1.310 \\
PTP & 0.088 & 1.308 \\
LTT & 0.088 & 1.308 \\
PPT & 0.265 & 0.512 \\
PPP & 0.520 & 0.361 \\
\hline
\end{tabular}

Key: T (tansig); P (purelin); L (logsig).

Table 6: Optimal models for Portfolio 8.

\begin{tabular}{|c|c|c|}
\hline \multicolumn{3}{|c|}{ Portfolio 8} \\
Activation Function Admixture & RMSE $_{\mathrm{tr}}(\%)$ & RMSE $_{\mathrm{ts}}(\%)$ \\
\hline TPT & 0.121 & 0.073 \\
TTT & 0.129 & 0.111 \\
TLT & 0.158 & 0.087 \\
TTP & 0.173 & 0.173 \\
LPT & 0.206 & 0.187 \\
LTT & 0.229 & 0.206 \\
PPT & 0.245 & 0.200 \\
PTT & 0.387 & 0.364 \\
PLP & 0.433 & 0.180 \\
LPP & 0.436 & 0.472 \\
PTP & 0.153 & 0.654 \\
PPP & 0.541 & 0.343 \\
LLT & 0.559 & 0.187 \\
LLP & 0.583 & 0.206 \\
PLT & 0.085 & 1.299 \\
LTP & 0.055 & 1.345 \\
\hline
\end{tabular}

Key: T (tansig); P (purelin); L (logsig).

Table 7: Optimal models for Portfolio 9.

\begin{tabular}{|c|c|c|}
\hline \multicolumn{2}{|c|}{ Portfolio 9 } \\
Activation Function Admixture & $\operatorname{RMSE}_{\mathrm{tr}}(\%)$ & $\mathrm{RMSE}_{\mathrm{ts}}(\%)$ \\
\hline PTT & 0.115 & 0.173 \\
TTT & 0.180 & 0.245 \\
TPT & 0.212 & 0.346
\end{tabular}




\begin{tabular}{|l|l|l|} 
PPT & 0.235 & 0.339 \\
LPT & 0.335 & 0.339 \\
TPP & 0.377 & 0.206 \\
LPP & 0.480 & 0.250 \\
PLT & 0.106 & 1.310 \\
PTP & 0.123 & 1.351 \\
LLT & 0.132 & 1.313 \\
PPP & 0.618 & 0.450 \\
TLP & 1.295 & 1.351 \\
LTT & 1.334 & 1.331 \\
TLT & 1.351 & 1.328 \\
LTP & 1.063 & 0.882 \\
\hline
\end{tabular}

Key: T (tansig); P (purelin); L (logsig).

Comparing the models presented in Tables 5, 6 and 7, we observe that the best model for training the current network is TPT. In addition to calculating the mean of returns for the first 7 shares based on stochastic dominance, the outputs resulted in $0.166 \%$ and $0.217 \%$ of errors for training data and test data, respectively. Therefore, the optimal parameters identified with the TPT model in the sevenshare portfolio included values of IW, LW and bias with respect to Tables 8, 9, 10 and 11 in the current network.

Table 8: IW values for TPT model in Portfolio 7.

\begin{tabular}{|c|c|c|c|c|c|c|c|c|c|}
\hline Trading Symbol & A.C.P & Afra & Arfa & Balas & Bemapna & Bepas & Besama & D.Toolid & Dey \\
\hline First Neuron & 0.0959 & 0.2574 & 0.0157 & -0.0241 & 0.0350 & -0.9787 & 0.7297 & -0.3943 & 0.9357 \\
\hline Second Neuron & -0.3658 & -0.4106 & -0.1682 & -0.9602 & -0.3834 & 0.9941 & -0.3444 & -0.4386 & 0.3068 \\
\hline Third Neuron & -0.5437 & -0.8257 & 0.5362 & -0.4468 & 0.4148 & 0.5026 & -0.1980 & -0.2016 & 0.1857 \\
\hline Fourth Neuron & -0.9949 & 0.8630 & -0.7698 & 0.0782 & 0.3608 & -0.1612 & 0.0127 & 0.7670 & -0.4657 \\
\hline Fifth Neuron & -0.1368 & -0.3162 & -0.8917 & -0.9031 & -0.0568 & 0.9999 & -0.2047 & -0.9954 & 0.9638 \\
\hline Trading Symbol & Fezarin & Foulay & Ghaminou & Ghashir & Ghachar & Hasina & Jam & K.B.C & Kemarjan \\
\hline First Neuron & -0.8205 & 0.9049 & 0.1490 & 0.3815 & -0.5453 & -0.1427 & -0.1103 & 0.7447 & 0.0015 \\
\hline Second Neuron & 0.7269 & 0.2241 & 0.9911 & 0.7123 & -0.0281 & 0.5567 & 0.3123 & -0.5274 & -0.2070 \\
\hline Third Neuron & -0.0055 & -0.7047 & 0.4494 & 0.1063 & -0.1262 & 0.8530 & -0.7011 & 0.9702 & 0.5917 \\
\hline Fourth Neuron & -0.4253 & 0.9974 & -0.8017 & 0.2419 & 0.6182 & -0.3956 & -0.4108 & 0.0589 & 0.3860 \\
\hline Fifth Neuron & -0.1551 & 0.3039 & 0.5387 & -0.3855 & -0.2846 & 0.9389 & 0.3399 & -0.9737 & -0.3595 \\
\hline Trading Symbol & Keshargh & Khorasan & Mafakher & Maroun & Mihan & Pakhsh & Sebagh & Semara & Sharanel \\
\hline First Neuron & -0.8784 & -0.5365 & -0.8989 & -0.3315 & -0.2824 & -0.4288 & 0.5074 & 0.6063 & 0.0211 \\
\hline Second Neuron & 0.1811 & 0.0940 & 0.0150 & 0.3598 & -0.6121 & 0.0250 & 0.4082 & -0.9926 & -0.4904 \\
\hline Third Neuron & 0.3424 & 0.7590 & -0.6520 & -0.5246 & 6 & -0.3686 & 0.7971 & -0.5355 & 0.0291 \\
\hline Fourth Neuron & 0.3506 & -0.2074 & 0.5282 & -0.1377 & 0.5378 & 0.0758 & 0.9981 & 0.118 & -0.7268 \\
\hline Fifth Neuron & -0.5008 & 0.2788 & 0.3961 & 0.3973 & -0.1644 & 0.0348 & 0.0713 & -0.9627 & 0.2351 \\
\hline Trading Symbol & Shepas & Sobhan & Touril & V.Gardesh & V.Gostar & V.Zamin & Zagros & Zangan & Zob \\
\hline First Neuron & 0.5202 & 0.6773 & -0.6560 & 0.7601 & -0.2011 & 0.9433 & 0.3289 & -0.1209 & 0.1694 \\
\hline Second Neuron & -0.6157 & -0.6657 & 0.9811 & -0.3099 & 0.4814 & 0.1751 & -0.8026 & 0.9281 & 0.1740 \\
\hline Third Neuron & 0.8710 & -0.9085 & 0.6477 & 0.1477 & -0.0712 & 0.4673 & 0.0159 & -0.5871 & -0.0539 \\
\hline Fourth Neuron & 0.0884 & 0.5137 & -0.9138 & 0.2605 & 0.0802 & -0.1804 & 0.1454 & -0.4714 & -0.2998 \\
\hline Fifth Neuron & -0.9471 & -0.1902 & 0.2079 & 0.0227 & 0.0986 & -0.0487 & -0.2855 & -0.2271 & -0.7517 \\
\hline
\end{tabular}

Table 9: LW values for TPT model in Portfolio 7. 


\begin{tabular}{|lccc|}
\hline Neuron & Sixth Neuron & Seventh Neuron & Eighth Neuron \\
\hline First Neuron & -0.3153 & -0.0864 & -0.0214 \\
Second Neuron & 0.0512 & 0.7903 & -0.3563 \\
Third Neuron & -0.5046 & 0.8847 & -0.5185 \\
Fourth Neuron & 0.4691 & 0.2059 & -0.0104 \\
Fifth Neuron & -0.0538 & -0.0197 & -0.4595 \\
\hline
\end{tabular}

Table 10: Bias values in the latent layer of TPT model in Portfolio 7.

\begin{tabular}{|c|cccccccc|}
\hline Neuron & First & Second & Third & Fourth & Fifth & Sixth & Seventh & Eighth \\
B & 0.3899 & -0.8003 & -0.3635 & -0.0108 & 0.0875 & 0.2715 & -0.2298 & -0.3136 \\
\hline
\end{tabular}

Table 11: Bias value in the output layer of TPT model in Portfolio 7.

\begin{tabular}{|c|c|}
\hline $\begin{array}{c}\text { Neuron } \\
\text { B }\end{array}$ & Output Neuron \\
\hline
\end{tabular}

Finally, we present complementary diagrams to demonstrate the accuracy of our training network by means of Figures 2, 3, 4 and 5. Figure 2 displays the network for the training data. The success of this network can be inferred from the diagram, although there was insufficient adaptability in the trained data for the specific cases of Hasina and Kemarjan. Figure 3 indicates the training of test data by this network and shows a close match between the test data and data tested by the network. According to this figure, the network performed well when applied to the test data. Figure 4 and Figure 5 indicate the dispersion of training data and test data around the fitness line (Ticknor, 2013). According to both figures, most returns were dispersed close to the line of best fit, a fact which indicates a good overall performance of this network.

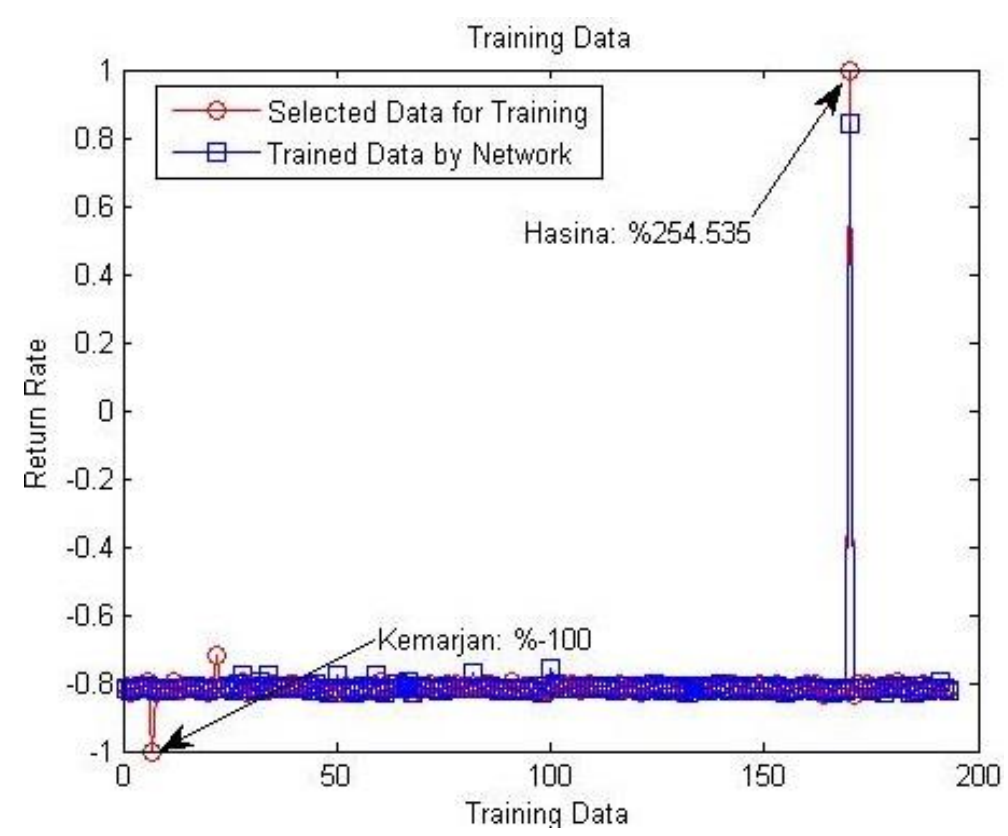

Figure 2: Training of training data. 


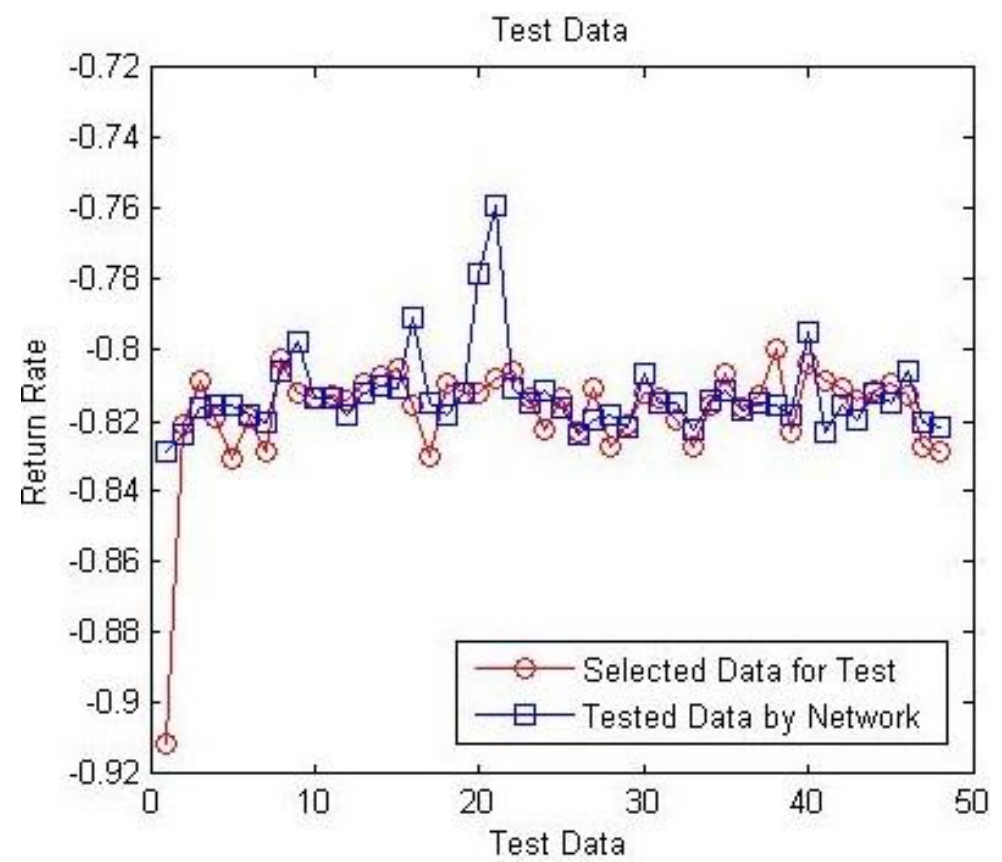

Figure 3: Training of test data.

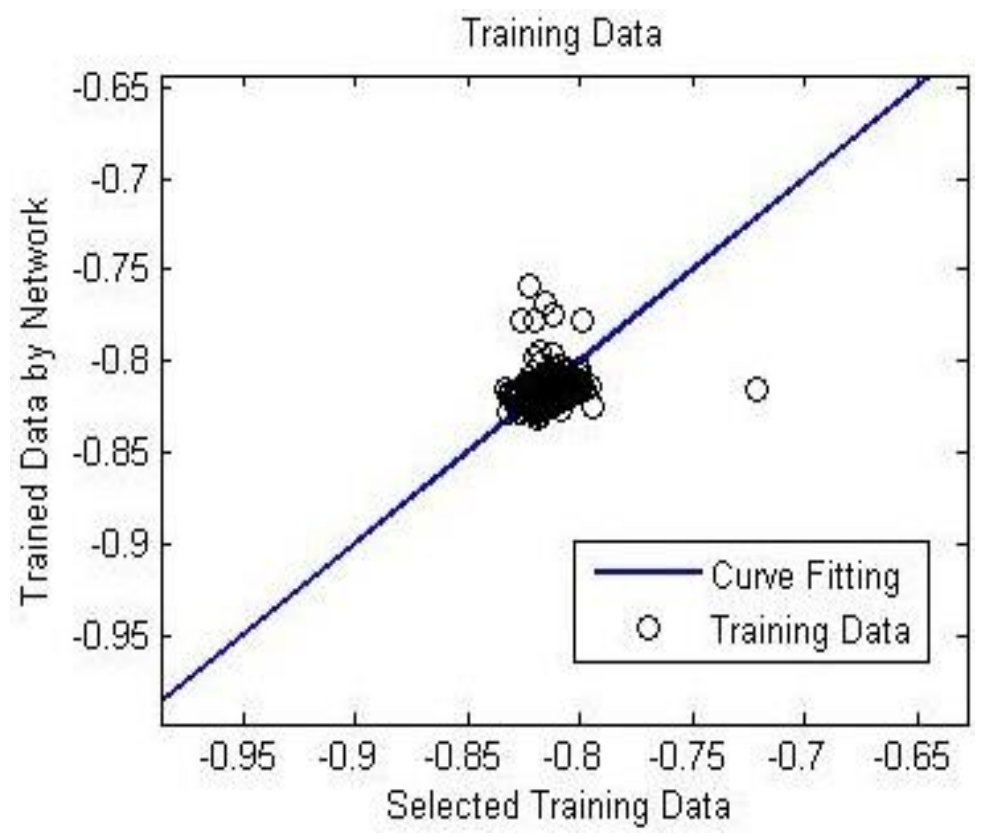

Figure 4: Dispersion of training data. 


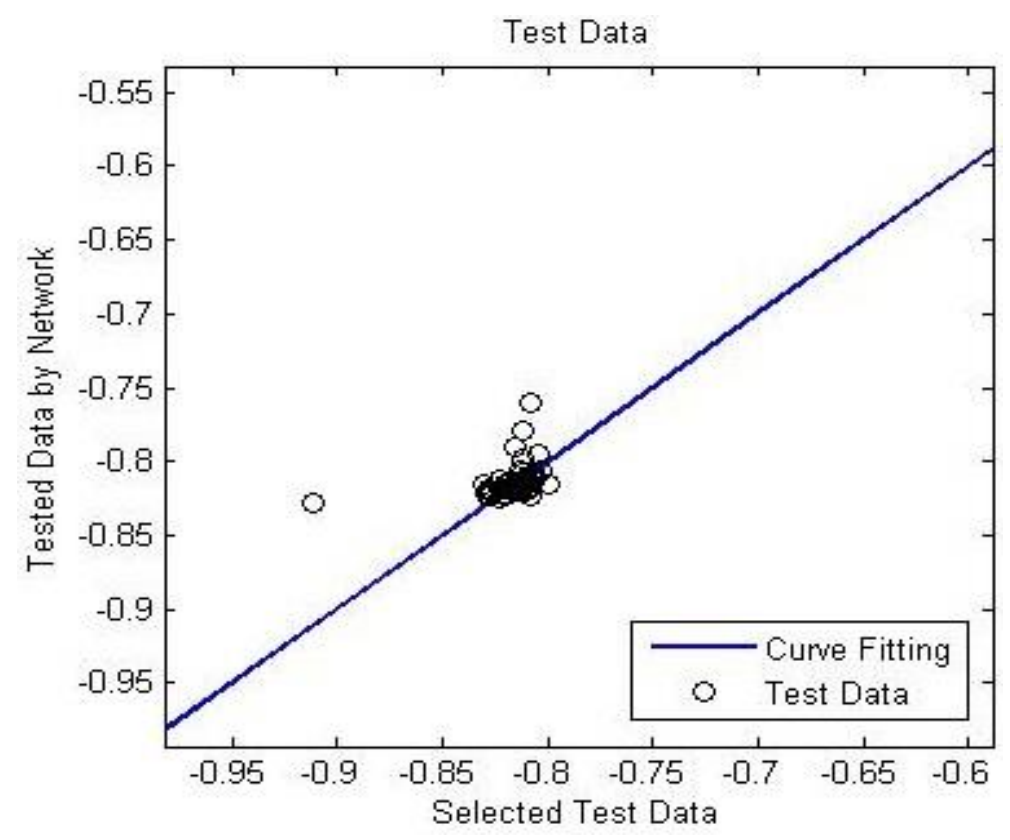

Figure 5: Dispersion of test data.

\section{Conclusion}

This study focussed on performance evaluation and portfolio optimization for OTC companies listed in Iran, a developing country, from $21^{\text {st }}$ March 2014 to $20^{\text {th }}$ March 2015. It also aimed to compare the efficiency of this research tool with other studies that were conducted in developed countries.

The period of time considered for investigation in this study included particular challenges and major changes in the political and economic status of Iran, which had a direct impact on the capital market. The weekly and daily returns of companies were used in order to evaluate the performances. Moreover, stochastic dominance was employed to analyse the rankings and the methodology was nonparametric to avoid restrictive distributional assumptions, so the approach was robust and efficient. Then this criterion and selected constraints were used to prepare an optimal portfolio along with a hybrid model combining the simple and trained ANN by PSO. Therefore, we also determined optimal parameters and activation functions.

Given the network used in this study, we considered 27 combinations of activation functions, including Tansig, Purelin and Logsig. We also considered 3 possible cases for investment in portfolios of 8,9 and 10 shares, so resulting in 81 research models for investigation. Finally, some of the combinations of activation functions were presented for Portfolios 7, 8 and 9 with respect to Tables 5, 6 and 7. Comparing them with one another, the combination of activation function TPT for Portfolio 7 was selected as the optimal combination resulting in $0.109 \%$ and $0.083 \%$ errors for the training and test data respectively, which were the smallest observed errors. Finally, the optimal values and weights were presented for the combination of activation function TPT in Tables 8, 9, 10 and 11. The information pertaining to the descriptive statistics of Iran OTC index and the orders of 
dominance among indices and other companies were presented in Tables 1 and 2 to investigate the accuracy of the research results and compliance with the real world.

According to Table 3, Portfolio 7 combined TPT functions as the optimal portfolio. It had 3 dominances of first order, 151 of second order and 33 of third order. Given the existence of FSD shares in this portfolio, the investors were provided with an opportunity to exploit arbitrage with respect to a justified area. The optimal Portfolio 8 had a better performance in comparison with Iran OTC in a way that it did not need to apply any cardinality limits. If necessary, slight changes can be made to strategies of investors, as they are resistant to events that can occur in critical and unstable conditions of capital market. However, due to the existence of SSD and TSD in this portfolio, reasonable stability against changes was indicated.

These findings confirmed the results achieved by Roman et al. (2013), Al-Khazali et al. (2014) and Hoang et al. (2015). Therefore, we expect this portfolio to result in abnormal return, according to the study conducted by Klard and Kassimatis (2014). In addition to Portfolio 7, investors can select Portfolios 8 and 9 as other investment options because they had more TSDs and SSDs than did Portfolio 7. This fact increases the resistance of these portfolios against critical and unstable conditions of the market, so fixing the effectiveness of the diversification principle in the investment portfolio. As there were large numbers of TSD and SSD among these portfolios, they are particularly appropriate for risk-averse investors.

The hybrid model combining ANN and PSO was seen to be considerably successful for generating optimal results and appropriate activation functions. These results were consistent with the theoretical findings of Das et al. (2013) and an application of the simple PSO in a study conducted by Pederson and Chipperfield (2010). Our research results also confirmed the efficiency of stochastic dominance criteria as noted in the studies conducted by Roman et al. (2013), ANN as in a study carried out by Kristijanpoller et al. (2014) and PSO as in studies conducted by Deng et al. (2012) and Liu et al. (2015). These studies were carried out in the capital markets of developed countries, whereas our analysis related to a developing country.

Therefore, we deduce that the tools and methods, the efficiency of which was proven in the capital markets of developed countries, also apply to, and demonstrate efficiency in, two novel applications of portfolio optimisation within developing countries. The first of these is gaining familiarity with the theory and practice of these research tools and the methods that enrich financial knowledge of investors in developing countries. The second of these is the application of tools and methods identified by investors in the capital markets of developing countries, which enables optimal allocation of financial resources and growth of the markets.

We expect that these findings will contribute to improving the economies of developing countries and so help with economic development and facilitation of improving trends. Due to the constant interaction of the capital market with the various economic sectors, any change in this market will have an impact upon sectors such as real estate, currency, gold, commodities etc. For example, if there 
is a period of economic prosperity in the real estate market, the stocks of companies active in this area will raise their stock prices. By considering the effective role of the capital market in the economic situation of countries, public policy-making is also affected by this phenomenon. Proper policymaking in developing countries is the way in which they can become developed countries. Moreover, it might guide managers and financial analysts towards new ways of thinking as part of the process of making successful portfolio decisions.

\section{References}

Alam A., Uddin M.M. and Yazdifar H. (2019). Financing behavior of R\&D investment in the emerging markets: The role of alliance and financial system, $R \& D$ Management, 49, 21-32.

Al-Khazali, O., Lean, H.H. and Samet, A. (2014). Do Islamic stock indexes outperform conventional stock indexes? A stochastic dominance approach. Pacific-Basin Finance Journal, 28, 29-46.

Araújo, R. de A., Oliveira, A.L.I. and Meira, S. (2015). A hybrid model for high-frequency stock market forecasting. Expert Systems with Applications, 42, 4081-4096.

Babaei, S., Sepehri, M.M. and Babaei, E. (2015). Multi-objective portfolio optimization considering the dependence structure of asset returns. European Journal of Operational Research, 244, 525-539.

Bagheri, A., Peyhani, H.M. and Akbari, M. (2014). Financial forecasting using ANFIS networks with quantum-behaved particle swarm optimization. Expert Systems with Applications, 41, 6235-6250.

Cabrerizo, F.J., Herrera-Viedma, E. and Pedrycz, W. (2013). A method based on PSO and granular computing of linguistic information to solve group decision making problems defined in heterogeneous contexts. European Journal of Operational Research, 230, 624-633.

Clark, E. and Kassimatis, K. (2014). Exploiting stochastic dominance to generate abnormal stock returns. Journal of Financial Markets, 20, 20-38.

Coulibaly, S.K., Erbao, C. and Mekongcho, T. M. (2018). Economic globalization, entrepreneurship, and development, Technological Forecasting \& Social Change, 127, 271-280.

Das, G., Pattnaik, P.K. and Padhy, S.K. (2013). Artificial neural network trained by particle swarm optimization for non-linear channel equalization. Expert Systems with Applications, 41, 3491-3496.

Deng, G.F., Lin, W.T. and Lo, C.C. (2012). Markowitz-based portfolio selection with cardinality constraints using improved particle swarm optimization. Expert Systems with Applications, 39, 45584566.

Denuit, M.M., Huang, R.J., Tzeng, L.Y. and Wang, C.W. (2014). Almost marginal conditional stochastic dominance. Journal of Banking and Finance, 41, 57-66. 
Fan, X., Li, S. and Tian, L. (2015). Chaotic characteristic identification for carbon price and a multilayer perceptron network prediction model. Expert Systems with Applications, 42, 3945-3952.

Fong, M.W. (2010). A stochastic dominance analysis of yen carry trade. Journal of Banking and Finance, 34, 1237-1246.

Gosciniak, I. (2014). A new approach to particle swarm optimization algorithm. Expert Systems with Applications, 42, 844-854.

Hadar J. and Russell W.R. (1971). Stochastic dominance and diversification. Journal of Economic Theory, 3, 288-305.

Hanoch, G. and Levy, H. (1969). The efficiency analysis of choices involving risk. Review of Economic Studies, 36, 335-346.

Hoang, T.H.V., Lean, H.H. and Wong, W.K. (2015). Is gold good for portfolio diversification? A stochastic dominance analysis of the Paris stock exchange. International Review of Financial Analysis, 42, 98-108.

Hsiao, H.F., Lin, L. and Yeh, C.C. (2019). Simple measures of exchange rate volatility: applying a combined artificial neural network and stochastic volatility model, Chimica Oggi-Chemistry Today, to appear.

Jensen, M.C. (1969). Risk, the pricing of capital assets and the evaluation of investment portfolios. Journal of Business, 42, 167-247.

Kennedy, J. and Eberhart, R. (1995). Particle swarm optimization. In Proceedings of the IEEE International Conference on Neural Networks, Perth, Australia.

Kristjanpoller, W., Fadic, A. and Minutolo, M.C. (2014). Volatility forecast using hybrid neural network models. Expert Systems with Applications, 41, 2437-2442.

Lean, H.H., McAleer, M. and Wong, W. (2010). Market efficiency of oil spot and futures: a meanvariance and stochastic dominance approach. Energy Economics, 32, 979-986.

Leboucher, C., Shin, H.S., Chelouah, R., Le Ménec, S., Siarry, P., Formoso, M., Tsourdos, A. and Kotenkoff, A. (2018). An enhanced particle swarm optimization method integrated with evolutionary game theory. IEEE Transactions on Games, 10, 221-230.

Levy, H. (2006). Stochastic Dominance: Investment Decision Making Under Uncertainty. Springer, New York.

Liu, J., Jin, X., Wang, T. and Yuan, Y. (2015). Robust multi-period portfolio model based on prospect theory and ALMV-PSO algorithm. Expert Systems with Applications, 42, 7252-7262.

Liu, Y., Wu, X. and Hao, F. (2012). A new chance-variance optimization criterion for portfolio selection in uncertain decision systems. Expert Systems with Applications, 39, 6514-6526. 
Markowitz, H. (1952). Portfolio selection. Journal of Finance, 7, 77-91.

Mendy, J., and Rahman, M. (2019). Supporting SMEs' internationalisation through a deeper understanding of human and technology barriers: applying effective HRM processes from a developing country. Journal of Organisational Effectiveness: People and Performance, 6(4), 205226.

Mertzanis, C. (2019). Family ties, institutions and financing constraints in developing countries, Journal of Banking \& Finance, $108,1-22$

Montes, I., Miranda, E. and Montes, S. (2014). Decision making with imprecise probabilities and utilities by means of statistical preference and stochastic dominance. European Journal of Operational Research, 234, 209-220.

Patel, J., Shah, S., Thakkar, P. and Kotecha, K. (2015a). Predicting stock and stock price index movement using trend deterministic data preparation and machine learning techniques. Expert Systems with Applications, 42, 259-268.

Patel, J., Shah, S., Thakkar, P. and Kotecha, K. (2015b). Predicting stock market index using fusion of machine learning techniques. Expert Systems with Applications, 42, 2162-2172.

Pedersen, M.E.H. and Chipperfield, A.J. (2010). Simplifying particle swarm optimization. Applied Soft Computing, 10, 618-628.

Post, T. and Kopa, M. (2013). General linear formulations of stochastic dominance criteria. European Journal of Operational Research, 230, 321-332.

Rahman, M. and Mendy, J. (2019). Evaluating people-related resilience and non-resilience barriers of SMEs' internationalisation: a developing country perspective. International Journal of Organizational Analysis, 27(2), 225-240.

Rahman M., Uddin M. and Lodorfos G. (2017). Barriers to enter into foreign markets: Evidence from SMEs in emerging market. International Marketing Review, 34, 68-86.

Ramos-Pérez, E., Alonso-González, P.J. and Núñez-Velázquez J.J. (2019). Forecasting volatility with a stacked model based on a hybridized Artificial Neural Network, Expert Systems with Applications, $129,1-9$.

Rather, A.M., Agarwal, A. and Sastry, V.N. (2015). Recurrent neural network and a hybrid model for prediction of stock returns. Expert Systems with Applications, 42, 3234-3241.

Riahi, Y. and Hammami Y. (2019). Accounting information and financial institutions' credit spreads: the case of Tunisia. Journal of Applied Accounting Research, 20(1), 2-21.

Roman, D., Mitra, G. and Zverovich, V. (2013). Enhanced indexation based on second-order stochastic dominance. European Journal of Operational Research, 228, 273-281. 
Rothschild, M. and Stiglitz, J.E. (1970). Increasing risk: a definition. Journal of Economic Theory, 2, 225-243.

Ticknor, J.L. (2013). A Bayesian regularized artificial neural network for stock market forecasting. Expert Systems with Applications, 40, 5501-5506.

Traynor. J.L. (1965). How to rate management of investment funds. Harvard Business Review, 43, 63-75.

Uddin M., Chowdhury A., Zafar S., Shafique S. and Liu J. (2019). Institutional determinants of inward FDI: evidence from Pakistan. International Business Review, 28, 344-358

Versijp, P.J.P.M. (2007). Advances in the Use of Stochastic Dominance in Asset Pricing. PhD thesis, Erasmus University Rotterdam.

Whitmore, G.A. (1970). Third-degree stochastic dominance. American Economic Review, 60 (3), $457-$ 459.

Wong, W.K. and Chan, R.H. (2008). Prospect and Markowitz stochastic dominance. Annals of Finance, 4, 105-129. 